\title{
A PRESENÇA DO KITSCH NA ROMARIA FREI BRUNO EM JOAÇABA - SANTA CATARINA
}

\section{THE PRESENCE OF KITSCH IN FREI BRUNO ROMA IN JOAÇABA - SANTA CATARINA}

Roberto Carlos Rodrigues ${ }^{1}$

\section{RESUMO}

O artigo tem como objetivo compreender o fenômeno kitsch e sua construção e analisar o seu papel no âmbito religioso. Será abordado de que forma podemos identificar sua presença na Romaria Frei Bruno, um importante evento religioso que está presente no calendário cultural do município de Joaçaba - SC. O trabalho busca ainda fazer reflexões sobre a necessidade do ser humano de acreditar em algo ou alguém, como o kitsch pode contribuir na construção de um ideal de esperança, crença e fé e suas interações com o indivíduo.

PALAVRAS-CHAVE: Kitsch; religião; crença; romaria.

\begin{abstract}
The article aims to understand the kitsch phenomenon and its construction and to analyze its role in the religious context. It will be approached in what way we can identify its presence in the Rom Frei Bruno, an important religious event that is present in the cultural calendar of the municipality of Joaçaba - SC. The work also seeks to reflect on the human being's need to believe in something or someone, such as kitsch can contribute to the construction of an ideal of hope, belief and faith and their interactions with the individual.
\end{abstract}

KEYWORDS: Kitsch; religion; belief; pilgrimage.

\section{INTRODUÇÃO}

O século XIX foi o século do surgimento, consolidação e transformação de muitas formas de pensar. Muitas ideologias se consolidaram nesse período, sendo possível destacar o fortalecimento das filosofias iluministas, o surgimento do espiritismo, nos EUA, do darwinismo e do socialismo, além de muitas outras filosofias

\footnotetext{
${ }^{1}$ Mestrando em História pela Universidade de Passo Fundo - UPF. Especialista em Metodologia de Ensino em História e Geografia, na área de Educação pelo Centro Universitário Barão de Mauá, Brasil (2014). Graduado em História pela Universidade do Oeste de Santa Catarina, - UNOESC, Brasil (2012).
} 
que nutriram os debates na academia e na sociedade. A segunda revolução industrial é fruto também desse século, a qual se expandiu a partir da segunda metade do século XIX e alterou significativamente o panorama estético do ocidente.

Esse fenômeno, além de impulsionar o desenvolvimento tecnológico, nutriu a produção artística na direção de novas possibilidades formais e ofereceu novos aparatos técnicos como a fotografia e o cinema, sendo que tal processo ampliou o acesso aos bens culturais. $\mathrm{O}$ consumo de tais bens, antes restrito à aristocracia, expandiu-se como nunca. Dentre as consequências dessa democratização está o kitsch.

Tendo esse quadro histórico como referência, esse trabalho analisa o fenômeno kitsch dentro do âmbito religioso. A experiência religiosa e experiência estética são complexos processos psicológicos que envolvem os sentidos, a cognição e o afeto. A experiência religiosa pode ser substituída pela experiência estética e o kitsch pode colaborar nessa perspectiva. Para o objetivo deste artigo, faz-se necessário explorar, no primeiro momento, a definição de kitsch dentro de sua epistemologia, compreender a sua relação com a arte e o seu significado, que é atribuído dentro da esfera religiosa, além de como o kitsch ajuda a materializar a experiência divina e religiosa.

Uma vez que para Arnheim (1987), o conteúdo espiritual da religião é corporificado, ou seja, trazido à condição da existência física, pela arte. Para a pessoa religiosa, diz Arnheim (1987), não basta aceitar, por exemplo, a existência de Deus: é preciso que essa existência seja sentida, reverberando na própria mente do fiel, de modo que, quando, no Livro de Jó, Deus responde do meio do redemoinho, o leitor seja esmagado pela grandeza da criação.

Será abordada a necessidade do ser humano em acomodar suas necessidades intrínsecas e como a religião ajuda a explorar essas necessidades que são inerentes a todos nós e estão muito evidentes na sociedade pós-moderna em que estamos inseridos. O trabalho abordará ainda a inserção da personagem Frei Bruno no cenário religioso no município de Joaçaba, Santa Catarina, e de que forma surgiu a Romaria Penitencial Frei Bruno e como o kitsch está presente nesse evento.

\section{DEFINIÇÃO DE KITSCH}

O termo kitsch é relativamente recente e incerto, vem ganhado cada vez mais adeptos e hoje é uma grande fonte de renda para pequenos comerciantes. Tal termo, geralmente, causa polêmica ao ser conceituado. O que para uns é a personificação do mau gosto, para outros é a prova do quanto o gosto popular pode ser autêntico. 
Acredita-se que tenha sido usado pela primeira vez em, cerca de 1860 ou 1870, na gíria dos pintores e negociantes de arte para designar os objetos de arte sem valor. Mais tarde, a palavra entrou no vocabulário dos vários países europeus, tornando-se, no final dos anos 20, uma palavra internacional (KULKA, 1996).

Abraham Moles, ao situar a origem da expressão kitsch, afirma o seguinte:

\begin{abstract}
A palavra Kitsch, no sentido moderno, aparece em Munique, por volta de 1860, palavra bem conhecida do alemão do sul: kitschen, quer dizer atravancar e, em particular, fazer móveis novos com velhos, é uma expressão bem conhecida; verkitschen, que quer dizer trapacear, receptar, vender alguma coisa em lugar do que havia sido combinado. Neste sentido, existe um pensamento ético pejorativo, uma negação do autêntico. (MOLES, 2001. p. 10).
\end{abstract}

Assim, Moles (2001) atrela o kitsch a um agir de má-fé, ao regateio, ao tirar vantagem de algo. Para Moles (2001), o Kitsch constitui um dos tipos de relação que o ser mantém com as coisas. Vai muito além de um objeto, ou mesmo um estilo. Esta origem do kitsch tem implicações éticas que, em maior ou menor grau, vão mediar suas relações durante toda sua evolução.

O autor destaca o kitsch religioso como sendo um dos grandes aspectos do kitsch. Para ele, por razões de eficácia, a religião está sujeita a apelos, a maioria captando a emoção dos desejos latentes das massas, efetuando sua disseminação, muitas vezes, através do kitsch. Sendo assim, negação do autêntico, cópia e artificialidade são os significados frequentemente associados aos objetos e produções kitsch, encontráveis tanto nas artes visuais, na literatura e na música, quanto no design e na profusão de produtos que cercam o cotidiano: souvenir turístico, miniatura, adorno, objeto de decoração e devoção, talismã religioso, entre outros.

Ainda que, muitas vezes, refira-se ao kitsch como um conceito universal, reconhecível, portanto em qualquer época e estilo artístico, a maior parte dos estudiosos encontra-o no seio da sociedade industrial, de feitio burguês, o que faz dele um dos produtos típicos da modernidade. Abraham Moles indica que o crescimento do kitsch coincide com a expansão do mercado e a emergência da sociedade de massa que impõe normas à produção artística ditadas pela difusão e possibilidades de aquisição de produtos artísticos, de modo geral, reproduções e cópias, em função dos baixos preços.

O kitsch apresenta-se, desse modo, como a arte que está ao alcance do homem sem grandes poderes aquisitivos e está disponível nas vitrinas e casas comerciais. As produções kitsch caracterizam-se pelo baixo preço e por seu caráter eminentemente 
decorativo, além de possuírem um grande caráter emocional para quem possui o objeto. No entanto, um objeto pode ser kitsch para uma sociedade ou cultura e obra de arte para outra. Quando afirmamos que algo é kitsch, o contexto em que está inserido deve ter sido analisado, pois conforme Moles (2001) uma coisa pode ser kitsch em um lugar e funcional no outro. Ele cita o exemplo em que um conjunto de candelabros pode ser kitsch em Paris e não ser na Itália, já que esse país teve sérios problemas de eletricidade em determinada época.

Beltrão, considerando a obra de Abraham Moles, em seu livro "O kitsch" (1971), através da chamada "tipologia do kitsch", conseguiu traçar um perfil bastante claro das propriedades de como se pode classificar um objeto de kitsch ou não:

\footnotetext{
A tipologia é aplicada a dois aspectos do kitsch: sobre peças isoladas, que por si só contêm toda uma carga da estética; e sobre grupos que, unidos num contexto específico, constituem um sistema kitsch, mesmo que ao serem vistos isoladamente não apresentem nenhum de seus sinais. Os indicadores que definem a presença do kitsch em objetos são: desproporção das dimensões geométricas em relação ao objeto representado - os souvenirs geralmente são providos dessa característica; uso de símbolos religiosos na produção de objetos profanos, deturpados em seu sentido; uso de elementos eróticos - artigos com formatos sugestivos ou sadomasoquistas, como chicotes e algemas, por exemplo; objetos com acabamento grosseiro ou feitos com material ordinário. (BELTRÃO; WAECHTER, 2008, p.37).
}

Beltrão e Waechter (2008) comentam ainda que kitsch são materiais imitando outros materiais, sendo que os elementos raramente se apresentam como tal: a madeira simula o mármore; o plástico, a porcelana; o tecido, uma pétala de flor; o bronze, o ouro. São disfarçados por verniz, pintura, gesso e tudo que possa, de acordo com o significado do termo kitsch, fazer uma mercadoria parecer-se com outra.

\section{O SER HUMANO BUSCA UMA RELIGIÃO}

O ser humano procura, através da religião, entender ou desvendar a complexidade de fenômenos do universo - o que a ciência não conseguiu explicar até os dias de hoje, e só encontra na fé a resposta para entender as três perguntas básicas de Aristóteles, as quais a ciência não responde: “Quem somos?”, "De onde viemos?", "Para aonde vamos?".

Ao ser analisada a trajetória da humanidade, verifica-se que a religião tem acompanhado o ser humano desde os seus primórdios, servindo como uma ponte de compreensão para diversos fatos supostamente incompreensíveis. Para que a 
dominação de uma nação fosse efetivada como um todo, a imposição da religião do conquistador às nações conquistadas era um fator considerável para que essa soberania prevalecesse sobre os colonizados, além de servir como conforto para esses povos.

Juntamente com a religião, vêm os dogmas, com o discurso de que devem ser aceitos, pois eram e são anunciados como vindos diretamente da parte de Deus. Com a religião, veio a crença, na tentativa de dar uma explicação a fatos inexplicáveis. A religião abafa o medo do desconhecido. A crença surge também de uma necessidade. $\mathrm{O}$ ser humano, na busca por suprir suas necessidades, sejam econômicas, afetivas ou físicas, por vezes, quando não vê solução, acaba aceitando qualquer alternativa para amenizar sua angústia e a crença faz com que o indivíduo se sinta motivado a atravessar uma situação de grande dificuldade.

A religião utiliza-se ainda de rituais que são expressões e gestos, em uma tentativa de aplainar e endireitar a estrada, para facilitar a comunhão com o suposto "ser supremo", de modo que o ser humano se faça pessoa e se sinta como ser vivo, assistido pela divindade, com o potencial de viver em harmonia com as virtudes do bem supremo. Os rituais são necessários para a consolidação da fé religiosa e são práticas comuns em várias denominações.

Vários são os rituais praticados pela fé cristã, sendo: oração, jejum, santa ceia, louvor, procissão, comunhão, dentre outros. Na região meio-oeste de Santa Catarina, uma prática de ritual fortemente vivenciada é a Romaria Frei Bruno, sobre a qual se discorrerá mais adiante. Tanto em Santa Catarina, quanto na região do meio-oeste catarinense, a Igreja Católica é a protagonista da fé cristã, tendo como um dos responsáveis Frei Bruno, personagem importantíssima para a consolidação da fé católica no Vale do Rio do Peixe.

\section{FREI BRUNO}

Filho de Humberto Linden e Cecília Golden, Humberto Linden Júnior nasceu em Dusseldorf, na Alemanha, em 08 de setembro de 1876. Com quase dezoito anos, ingressou no noviciado dos Franciscanos da Saxônia, em Harreveld, na Holanda. Tomou hábito em 13 de março de 1894 e destinado à missão brasileira, trocou a novicidade da Saxônia por um transatlântico que o levou a Salvador, Bahia, em 12 de julho de 1894, onde completou o noviciado e fez profissão solene em 15 de maio de 1898. Encaminhou-se, então, para o sacerdócio, estudando filosofia e teologia, sendo 
ordenado sacerdote em 10 de maio de 1901, em Petrópolis, Rio de Janeiro, onde permaneceu por mais dois anos. Em 1904, foi para a cidade de Gaspar, Santa Catarina, para atuar como superior e vigário. Continuou no mesmo lugar mais três anos como coadjutor. Bruno foi transferido para São José, Santa Catarina, onde mais tarde confiaram-lhe o cargo de vigário da paróquia. Em 1917, foi transferido para a cidade de Não-Me-Toque, Rio Grande do Sul, como superior e vigário (ZÍLIO, 1998).

De 1926 a 1945, teve longa estada em Rodeio, Santa Catarina, no convento do Noviciado, onde era guardião e vigário. Edificou, sem cessar, por quase 20 anos, com seu exemplo de autêntico frade menor. Assumiu o cargo de diretor da então Companhia das Irmãs Catequistas e fez muitas reformas e construções de novas capelas. Após comemorar dezenove anos de vigário e festejar, em 13 de maio de 1944, seu jubileu Áureo Franciscano (50 anos de vida religiosa), foi destacado para trabalhar no distrito de Esteves Júnior, onde permaneceu poucos meses, pois, no fim do mesmo ano, foi designado superior e pároco de Xaxim, Santa Catarina, até 1956 (ZÍLIO, 1998).

Octogenário, veio para Joaçaba e, no então distrito de Luzerna, passou uma temporada de repouso. A pedido dos confrades, descobriu novas oportunidades de apostolado, o que o dispôs a atuar, a partir de 02 de fevereiro de 1956, em Joaçaba. Os últimos quatro anos não foram nada mais que a continuação de um apostolado que Frei Bruno já vinha praticando há anos. Tinha uma predileção por longas e contínuas caminhadas, visitando famílias, benzendo casas, legalizando uniões, visitando doentes (ZÍLIO, 1998).

Frei Bruno foi encontrado morto em seu quarto pelo seu companheiro Frei Edgar, no dia 25 de fevereiro de 1960, e rapidamente se espalhou a notícia do falecimento do Frei. No dia 26 de fevereiro, o comércio e as indústrias fecharam em sinal de luto. Os motoristas de Joaçaba renderam uma homenagem em particular à memória de Frei Bruno, organizando um grande cortejo, rumando de noite à matriz, onde todos, ajoelhados na escadaria da igreja, rezaram pela alma do religioso (ZÍLIO, 1998).

Frei Bruno foi uma importante personagem que marcou a vida religiosa de Joaçaba e região. Sua história ainda marca a trajetória cultural e, por que não, econômica do Município, através da popular Romaria Frei Bruno. Alguns devotos o consideram santo devido às graças alcançadas por seu intermédio. Seu nome é conhecido em toda a região meio-oeste de Santa Catarina e está presente em diversas obras, como hospitais, ginásios, escolas e bairros. 


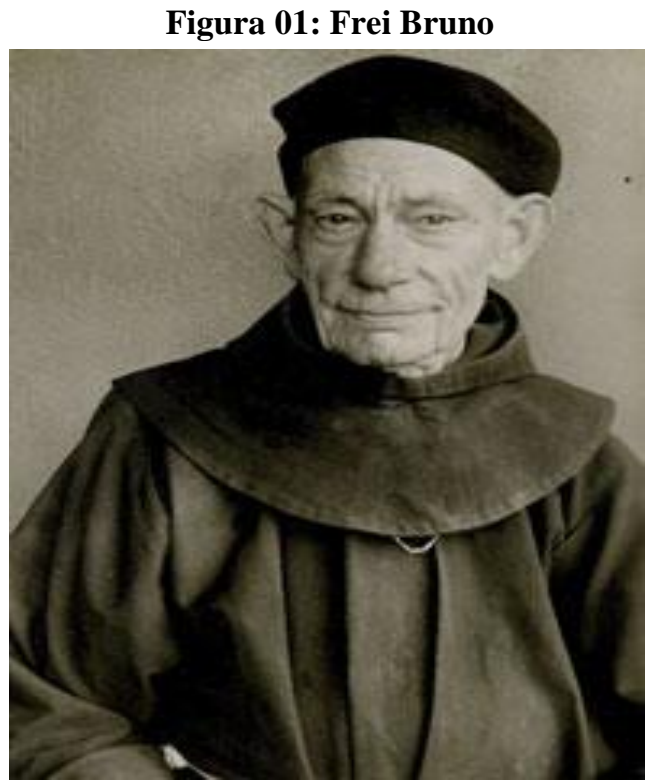

Fonte: Site - cnbb.org.br ${ }^{2}$

\section{ORIGEM DA ROMARIA FREI BRUNO}

A Romaria foi idealizada por Iraí Zílio, vereador do município de Joaçaba, em 1987. Ele era devoto de Frei Bruno, passava por um grave problema de saúde e estava internado no Hospital em Curitiba, sendo que, após sair do hospital, prometeu fazer uma romaria em homenagem ao Frei. Frei Neotti, em seu livro sobre a vida de Frei Bruno, descreve a iniciativa de Iraí: “[...] eu tinha minhas orações e então comecei a refletir: agora eu vou assumir um compromisso e faço uma promessa; quando retornar a Joaçaba, vamos organizar romarias todos os anos para o Frei Bruno [...]” (NEOTTI, 2014, p. 243).

\footnotetext{
${ }^{2}$ Disponível em: http://www.cnbb.org.br/vaticano-concede-nada-obstat-a-beatificacao-de-frei-bruno/. Acesso em 29 mai. 2019.
} 
A primeira romaria aconteceu em fevereiro de 1987, observando-se o mês do falecimento do Frei Bruno e, até hoje, é organizada sempre no último domingo de fevereiro, no município de Joaçaba, Santa Catarina. No início, enfrentou alguns obstáculos, como comenta Zílio: “O vigário da paróquia de Joaçaba achava que a Romaria não deveria acontecer todos os anos, mas os devotos persistiram e o povo aderiu de maneira espontânea" (ZÍLIO, 1998, p. 49).

A Romaria Penitencial, que ocorre no município de Joaçaba, tem como ponto de saída a Catedral Santa Terezinha e segue sob forma de caminhada até o cemitério municipal, trajeto esse de um pouco mais de três quilômetros. Quando da chegada ao cemitério, é celebrada uma missa no Jazigo de Frei Bruno.

A romaria conta com a participação de idosos, adultos, jovens e crianças, sendo que, no início, contava com a participação de cerca de dez mil pessoas e, hoje, passa de cinquenta mil o número de devotos, vindos de diversos municípios da região e de várias localidades distantes. Hoje, a Romaria é uma das maiores demonstrações da fé católica no estado de Santa Catarina.

\section{MONUMENTO COLOSSAL AO FREI BRUNO}

Em 2001, começou a execução do projeto para construção de um monumento em homenagem ao Frei e a Câmara de Dirigentes Lojistas de Joaçaba coordenou tal projeto, que começou a ser construído em um terreno doado pela família Montenegro de Oliveira, no Morro Panorâmico, um dos pontos mais altos do município, com vista para as cidades de Joaçaba e Herval d'Oeste.

Em 2004, começaram os trabalhos para a montagem das peças e, em 2005, os trabalhos para o revestimento, que duraram, aproximadamente, seis meses. O monumento foi inaugurado em 2008 e é considerado o terceiro maior das Américas, com trinta e sete metros de altura, pesando cerca de duas toneladas e meia, sendo menor apenas que o Cristo Redentor (com quarenta metros de altura) e que a Estátua da Liberdade (com cinquenta e sete metros de altura). A imagem foi construída em isopor pelo artista plástico Cláudio Silva e revestida em fibra de vidro.

Atualmente, o monumento Frei Bruno consolida-se como um importante ponto turístico, não somente para a cidade de Joaçaba e região, mas também para todo o estado de Santa Catarina, recebendo centenas de visitantes diariamente. 
No início, o monumento também contava com o Museu do Frei Bruno, que atualmente está localizado na sede da Paróquia e conta um pouco sobre a história do Frei, tendo em seu acervo, certidão de nascimento e óbito de Frei Bruno, diversas imagens fotográficas de sua localidade de nascença e do seminário onde ele estudou, na Alemanha, além de bilhetes e cartas, gravações de depoimentos das graças alcançadas por seus devotos e mais arquivos históricos.

Figura 02: Monumento Frei Bruno

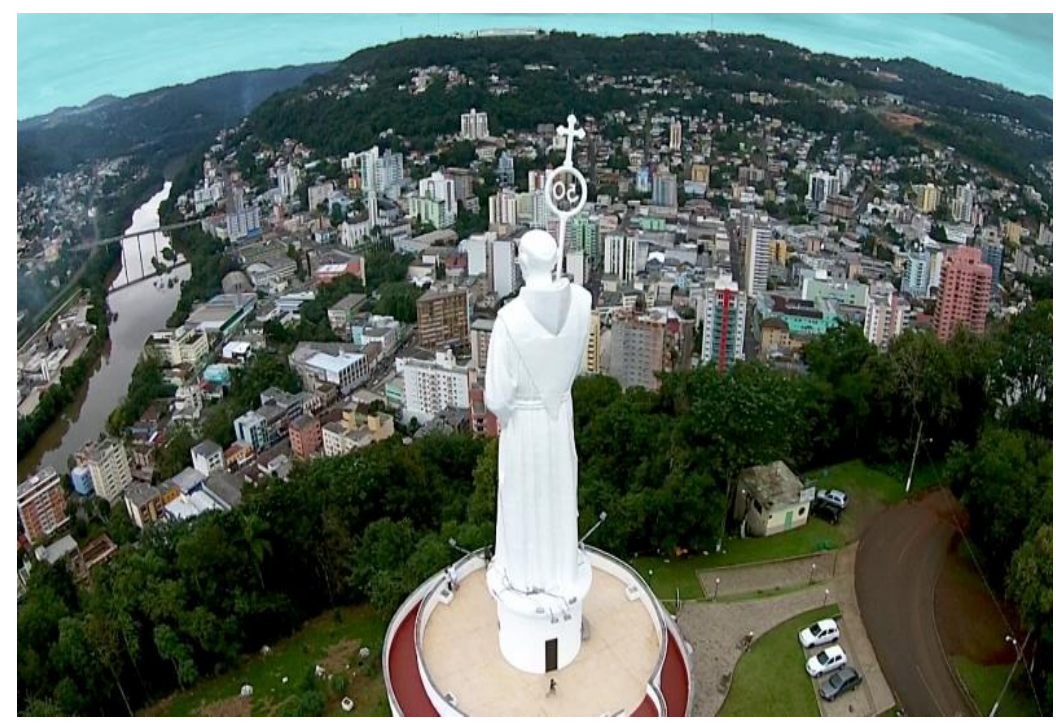

Fonte: CDL Joaçaba ${ }^{3}$

Em 2013, dá-se o processo de beatificação de Frei Bruno, o qual hoje prossegue dentro do que era esperado pela Comissão Histórica e pelo Tribunal Eclesiástico. Dom Mário Marquez, bispo da Diocese de Joaçaba, explica que estão avançados os trabalhos das pessoas envolvidas na missão de comprovar a santidade do religioso, que já reúne milhares de devotos em várias regiões do país.

\section{KITSCH DENTRO DA RELIGIÃO}

O kitsch está a desafiar as pessoas a viverem emoções e uma experiência completa do sagrado com a cosmovisão cristã em materializar, personificar a fé e a crença. No kitsch, a arte e a religião se fundem na perspectiva de levar o indivíduo a uma experiência real com o divino, com o sagrado.

\footnotetext{
${ }^{3}$ Disponível em: http://www.cdljoacaba.com.br/monumento-frei-bruno. Acesso em 29 mai. 2019.
} 
O kitsch religioso vai muito além da estética ou defeito de forma, existindo um significado teológico sobre os objetos kitsch que estão presentes na religião. Para o mundo religioso é indiferente saber o tipo de "arte" que é praticado para elaborar os objetos kitsch, o significado e os motivos teológicos estão acima da arte, da estética do "belo". A tentativa de impressionar na elaboração e demonstração de grandes obras de personagens cristãs através da arte não fará muita diferença no universo religioso, uma vez que o significado dogmático é muito mais relevante que as medidas, cores, traços, etc.

Gerson (2015) confirma que o Kitsch não tem preocupação em atender os padrões da arte e sim atender a experiência transcendental do individuo:

\begin{abstract}
O kitsch, entendido enquanto estilo, é a expressão de um projeto que renuncia a qualquer pretensão de atender aos valores tradicionais da arte, como a verdade e a autenticidade. Em outra direção, substitui tais valores por critérios de sensibilidade individual, apostando na ficção, na citação e na reprodução em série. Um exemplo bastante claro da dinâmica do "estilo kitsch" está no consumo de objetos religiosos. Tais objetos (imagens, estatuetas, etc.) simulam algo que, simbolicamente, une o espectador a uma força transcendental, mas que, originariamente, saiu de um molde que deu forma a produtos suficientes para que outras centenas de milhares de pessoas comprassem a mesma experiência transcendental (TROMBETTA, 2015, p. 443).
\end{abstract}

É no plano espiritual, psíquico, sentimental, moral, que determinar-se-ão as formas dos objetos religiosos e com isso guiarão a devoção dos fieis, que com a posse desses objetos poderão transcender sua fé, criando no seu íntimo a sensação de segurança, esperança e conforto das suas frustrações.

O kitsch não somente é um produto da industrialização e da cultura de massa. Ele também é fruto da sociedade pós-moderna, que é uma sociedade considerada a partir da satisfação imediata, do prazer de comprar e de se renovar com o acesso aos objetos de consumo ou cópia dos mesmos.

Almeida, Monteiro e Gonçalves (2013), comentam que o fenômeno moderno do kitsch foi criado para preencher um vazio. A demarcação do tempo de lazer fora do horário de trabalho fixo, com sua promessa de diversão e prazer concentrado dentro desse tempo, constituiu uma força empurrada para a formação de uma cultura que se adapta às necessidades dos novos clientes que você precisa para consumir. Este novo trabalhador urbano, apresentado no trabalho de fábrica ou no escritório para um regime estrito, pode compensar esta rendição da autonomia pessoal com uma intensa ocupação do seu tempo livre, transferindo a busca de identidade individual e emocionais a 
experiências simbólicas, agora definidas como lazer específico. Alcançando assim a racionalidade moderna e eficiente, define-se a combinação perfeita para o "novo indivíduo moderno", e a conversão da cultura em mercadoria reprodutível são alcançados. Portanto, o indivíduo moderno tem satisfeita a sua necessidade cultural através da materialidade do objeto de consumo.

De acordo com Chistina Pedrozza Sêga (2008), tratando-se de imitação, o kitsch serve tanto à arte, quanto aos objetos não artísticos. A satisfação em ter aquele objeto, mesmo sabendo muitas vezes que se trata de uma imitação, torna-se imensa por ele estar próximo ao objeto real. Com a aquisição desse objeto, o indivíduo percebe que estabeleceu uma relação de aproximação e de interação entre ele e a sociedade de consumo ou sociedade de massa.

O kitsch, apesar da possibilidade de sua produção em massa, não perde a sua singularidade, pois isso é algo intrínseco de cada objeto e é atribuído pelo indivíduo que o adquiri. Se o indivíduo adere à prática de sua coleção, não quebra o vínculo de particularidade com cada um dos objetos, pois cada objeto tem um "valor sentimental", uma história, uma promessa, um sacrifício alcançado e pode alcançar uma estima superior aos objetos mais valiosos.

Ao contrário da arte contemporânea, que em suas formas mais radicais pretende a subversão do sistema, criando novos parâmetros culturais, perceptivos e ideológicos, o objetivo do kitsch religioso não é formar um padrão estético, nem desafiar o status quo, mas sim agradar ao maior número de pessoas possíveis, satisfazendo às expectativas já existentes e fortalecendo a crença ideológica cristã. É objetivo do kitsch explorar impulsos humanos básicos relativos à família, à raça, à nação, ao amor, à nostalgia, às crenças religiosas, podendo tornar-se mais do que uma preferência estética, mas uma forma de vida. No caso do kitsch religioso, esse tende a ajudar na busca de respostas aos questionamentos que a ciência e a justiça não conseguem suprir em sua totalidade e, com isso, na motivação para encarar o lado desumano dos problemas da existência humana e das injustiças sociais. Para Abraham Moles (2001), o kitsch é "a arte da felicidade" e por que não dizer também que o kitsch religioso é a "constante busca da felicidade e da esperança?".

Nas religiões salvacionistas, o mundo é concebido como essencialmente mau, o que impõe a necessidade de uma libertação definitiva, fundada em uma ética de gratificação e em uma perspectiva evolucionista da vida, seja aqui nessa vida ou no mundo metafísico e o kitsch religioso é a ligação para essa cosmovisão. 
A sociedade moderna desencadeou o nascimento de um sentimento de ansiedade diante da impermanência das coisas e da instabilidade das tradições. Isso converge com a crítica política de que o kitsch serve como um sedativo para as dores do mundo, e o imaginário cristão transborda de representações adocicadas e pré-digeridas da promessa da recompensa por sua fidelidade ao ideário cristão, tornando-se, assim, o kitsch em produtos para consumo, proporcionando conforto imediato e incitando respostas previsíveis sem a necessidade de profundas reflexões.

A arte religiosa é, em sua maioria, kitsch, na medida em que intenciona, sobretudo, atender aos desejos e a fé de sua "massa", que também reclama por um apelo emocional. A esse respeito, Moles comenta:

Na medida em que a religião secular faz uso, segundo uma tradição corrente, da emoção estética que ela recupera a seu favor, está espontaneamente propensa, por razões de eficácia, a fazer um apelo à maioria, e por esta via, a adaptar as normas da arte aos desejos latentes da maioria, na medida em que a religião é capaz de captar essa emoção (MOLES, 2001, p. 48).

Assim, observa-se alguma relação de aproximação dos elementos estéticos do kitsch, que configuram uma ordem cheia de exageros e discrepâncias, sobreposições de formas e cores. Fernandes (2003) comenta que o kitsch religioso se caracteriza por parafernálias vendidas nos sites e lojas católicas, que vão desde bijuterias até pequenas coleções de livros de autoajuda.

Aí surge uma chamada "banalização da espiritualidade", que empurra a crença para a crendice, onde tudo parece ter um valor religioso: das orações de santinhos aos incensos curativos, das bijuterias aos livros religiosos de autoajuda. $\mathrm{O}$ acúmulo de devoções corresponde a um estado de privação, a uma debilidade do ser, a uma necessidade de religação que, subliminarmente, o kitsch assegura enquanto ícone de religiosidade, encantamento, contemplação. Sendo assim, o kitsch religioso tende a criar uma consciência coletiva.

Na Romaria Frei Bruno, o kitsch está presente, seja através de lembranças, enfeites para o interior das casas, ornamentação para roupas, ou objetos para prestar culto ao Frei. Em uma sociedade como a de hoje, sujeita a alterações econômicas, que se refletem na inflação, alterando os preços de forma imprevisível, o funcional deverá desempenhar, no mínimo, duas funções. Um exemplo disso, citado por Abraham Moles (2001, p. 205-216) em seu livro "O Kitsch" é uma peça que desempenha até três 
funções: saca-rolha, abridor de latas e de garrafa, em um único objeto. O kitsch não é antifuncional, ao contrário, ele acaba adotando uma característica pragmática e utilitária. Um dos objetos kitsch comercializados, tanto no início, quanto no término da Romaria, é o porta-chaves, que pode ter várias funções, as quais vão desde um simples porta-chaves até um objeto de caráter meramente decorativo e devocional, que o devoto pode levar para a sua casa após a compra, tendo, assim, também uma lembrança do evento, que para esse devoto do Frei pode ter uma "bagagem emocional" de grande relevância para a sua devoção.

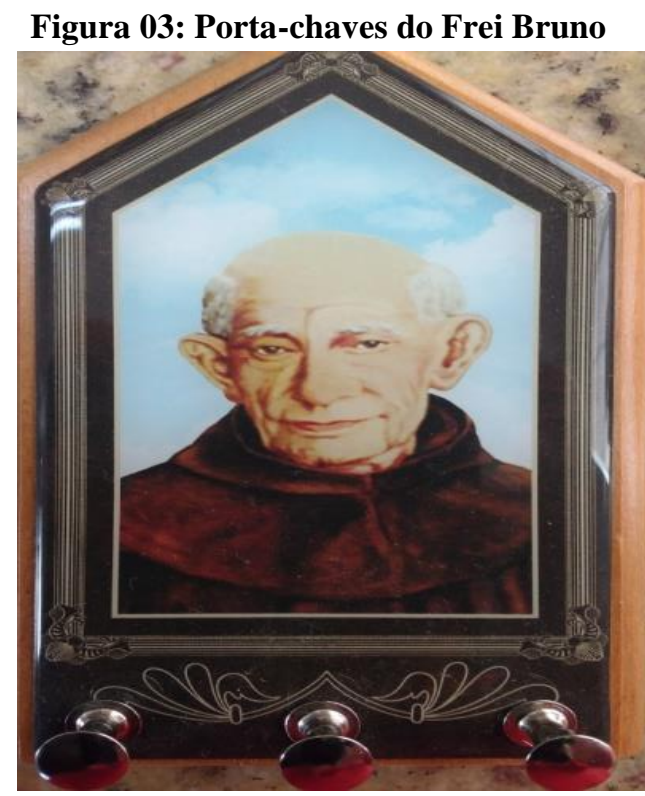

Fonte: Próprio autor

O kitsch, assim, "surgiu como reação a normas rígidas que tiveram origem no funcionalismo", como consideram Guimaraens e Cavalcanti (1979, p. 27). Outro objeto que possui multifuncionalidade, o qual é comercializado na Romaria, é o mini terço, chamado de uma dezena, que é personalizado com a imagem do Frei Bruno. Possui a função do terço, que é um instrumento da prática católica, com o qual os fiéis fazem um conjunto de orações (cinquenta orações de Ave Maria e um Pai Nosso, para completar um ciclo de orações do terço), sendo que, para que o devoto não necessite andar com um terço completo no seu cotidiano, pode optar por utilizar uma dezena ou mini terço, que não desperta tanta atenção, caso deseje fazer suas preces ao caminhar pela rua ou em outros lugares. Realizando cinco ciclos de orações com o mini terço, o devoto completará um ciclo de um terço tradicional. Além da função de terço, o mini terço tem função de chaveiro, que pode ser utilizado no dia a dia. 


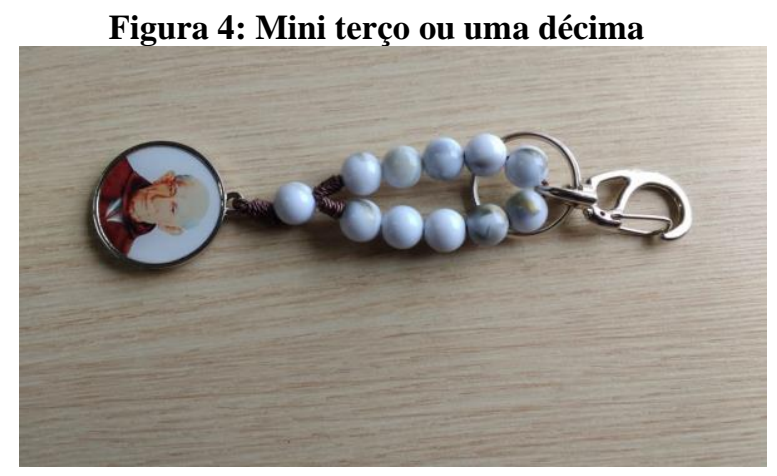

Fonte: Próprio autor

A seguir, podemos identificar outro objeto do kitsch religioso presente para comercialização na Romaria, o qual se trata de uma vela de parafina decorativa para o interior de residência com a foto do Frei Bruno ao fundo da cera. Essa vela é puramente decorativa e não serve para ser acessa, uma vez que o cordão da vela de parafina possui poucos centímetros. Sendo assim, objetos considerados por intelectuais como kitsch, aparentemente sem valor estético artístico, entram nessa lógica como objetos de decoração, recordação, de celebração e de identificação, como defendeu McDannell (1995).

Figura 5: Vela decorativa de parafina

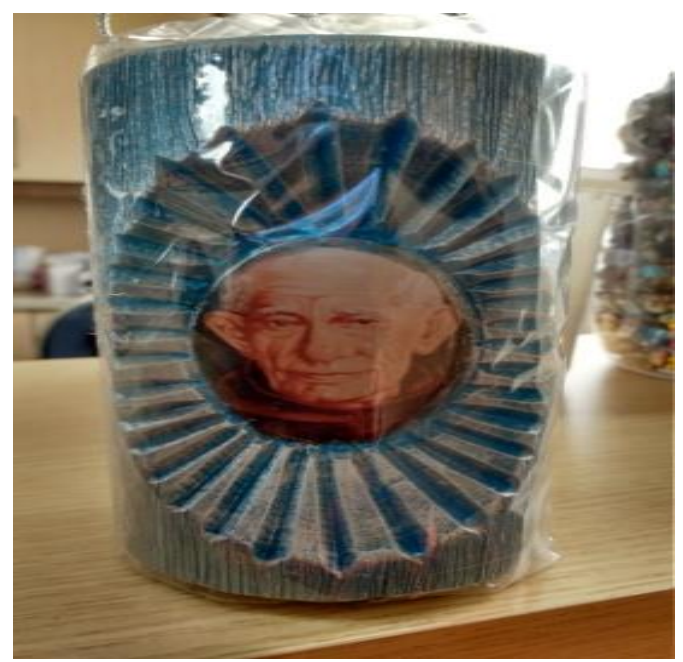

Fonte: Próprio autor. 
Vários são os objetos comercializados na Romaria Frei Bruno. O artista brasileiro Nelson Leirner (2006) em seu trabalho "Monalisas" (2003), mostra a personificação da Monalisa em bijuterias, que vão desde broches, brincos, canetas até isqueiros, etc, transformando-se em uma coleção kitsch que foi vendida pela loja do Museu do Louvre, de onde o artista retirou a maioria dos objetos que expôs, posteriormente, no Museu de Arte Contemporânea de Niterói, Rio de Janeiro. De forma semelhante, podemos perceber que a Romaria Frei Bruno também é palco da venda de algumas bijuterias do kitsch religioso, cujo principal atrativo é a personificação do Frei Bruno em objetos que podem ser utilizados no dia a dia dos devotos.

$\mathrm{Na}$ figura abaixo, podemos visualizar abotoaduras para roupas com a imagem do Frei Bruno, um dessas bijuterias encontradas para comercialização na Romaria. São várias peças oferecidas a preços bem acessíveis.

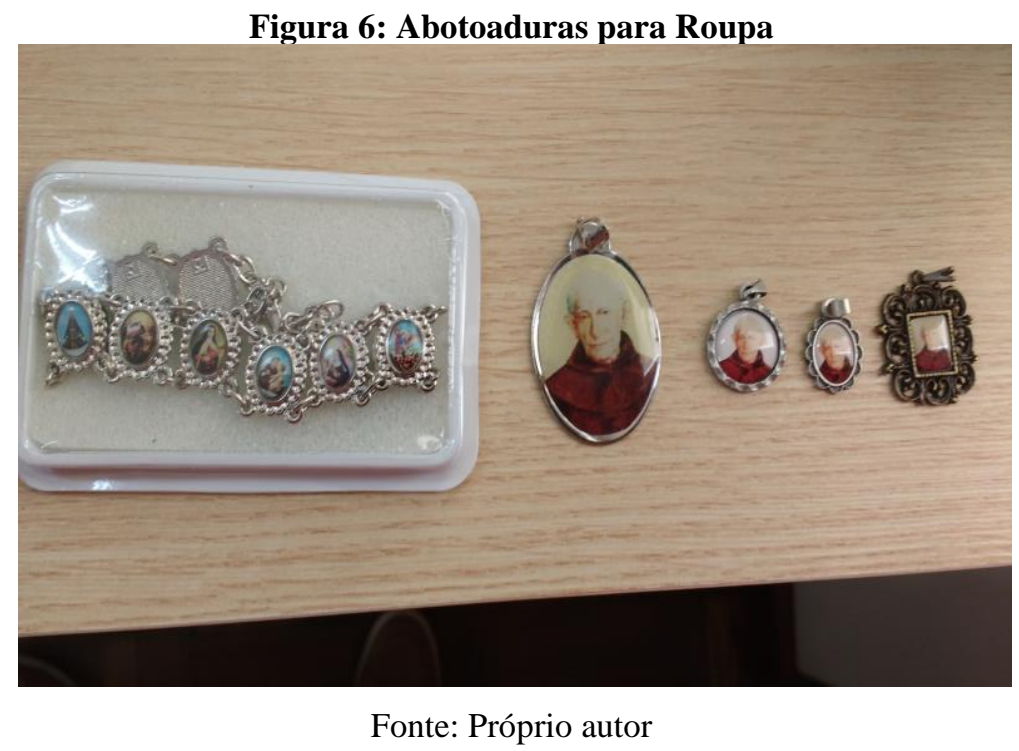

Esses objetos, como já mencionado anteriormente, possuem um valor bem acessível ao consumidor e, em virtude da sua grande procura pelos devotos da Romaria, ocasionou um aumento na demanda, razão pela qual a paróquia de Joaçaba agora está contratando empresas para produzirem em série esses objetos personalizados do Frei. Moles (2001, p. 20) menciona que "o fenômeno kitsch baseia-se em uma civilização consumidora que produz para consumir e cria para produzir, em um ciclo cultural”. Essa produção em série e em grande quantidade fez com que os produtos personalizados do Frei Bruno tivessem os preços mais accessíveis aos devotos, incentivando, dessa forma, 
o consumo do kitsch religioso entre os devotos desse frade, tornando a Romaria, como diria Moles (2001) "um verdadeiro templo de venda de produtos kitsch".

\section{CONSIDERAÇÕES FINAIS}

O kitsch, no âmbito religioso, serve como um sedativo para as dores do indivíduo e o imaginário cristão transborda de representações com a promessa do conforto espiritual e alcance da graça tão desejada. Sendo assim, o kitsch torna-se produto para consumo das massas, uma vez que seu acesso é facilitado pelo baixo preço e seu custo de produção também é baixo, contribuindo assim, com a sua comercialização. O kitsch comercializado na Romaria Frei Bruno tem um grande significado emocional para os devotos do frade e está presente na maioria dos lares católicos da região de Joaçaba.

Os devotos do Frei Bruno, que participam todos os anos da romaria, pertencem a diferentes classes sociais: tanto da alta sociedade, quanto de classes menos favorecidas, e a romaria estimula o consumo do kitsch, uma vez que esse não tem compromisso com a divisão de classes, mas seu compromisso é o de fazer parte da fé da crença do devoto. O kitsch não tem compromisso com a beleza, com a estética, mas sim com o conforto imediato, incitando respostas previsíveis sem a necessidade de profundas reflexões.

Destarte, o kitsch religioso, em especial os que são comercializados na Romaria Frei Bruno, é a materialização da esperança e crença de um futuro melhor para devotos do Frei Bruno.

Através desse artigo, não se espera esgotar a temática sobre o papel do kitsch no âmbito religioso, mas sim contribuir como fonte de pesquisa para futuros trabalhos. Entende-se que a continuação deste estudo é fundamental para podermos compreender o papel do kitsch nos eventos de diferentes denominações religiosas.

\section{REFERÊNCIAS BIBLIOGRÁFICAS}

ARNHEIM, R. Aesthetics. Visual aesthetics. Em M. Eliade (Org.), The Encyclopaedia of Religion. Vol.1, p. 47-51. New York, NY: Macmillan. 1987.

ALMEIDA, Marília; MONTEIRO Taís; GONÇALVES Osmar. O kitsch e a cultura de massa. Intercom, $\mathrm{RN}$ [online]. Disponível em: http://portalintercom.org.br/anais/nordeste2013/resumos/R37-1157-1.pdf. Acesso em 20 mai. 2019. 
BELTRÃO, Hallina; WAECHTER, Hans. Eu $\bullet$ kitsch: uma análise da atitude kitsch na obra de Pedro Almodóvar. Infodesing, São Paulo, v. 5, n. 1, p. $36-44$ [online]. Disponivel em: https://www.infodesign.org.br/infodesign/article/view/48. Acesso em 20 mai. 2019.

CARDOSO, Darlete. A transgressão da arte: uma análise semiótica do Kitsch. Revista Científica Plural. Edição 001. Janeiro de 2008.

FERNANDES, S. R. Catolicismo, massa e revival: Padre Marcelo Rossi e o modelo kitsch. Cadernos de Campo (São Paulo 1991), v. 11, n. 11, p. 87-98, 30 mar. 2003.

GUIMARAENS, D. e CAVALCANTI, L. Arquitetura e kitsch. Rio de Janeiro: FUNARTE, 1979.

KULKA, Thomas. Kitsch and Art. Pennsylvania: The Pennsyl- vania State University. 1996

LEIRNER, Nelson. Porque Museu? Niterói. MAC, 2006.

McDANNELL, Colleen. Material Christianity, Religion and Popular Culture in America. New Haven, Connecticut: Yale University Press, 1995.

MOLES, Abraham. O Kitsch: a arte da felicidade. Tradução de Sergio Miceli. São Paulo: Editora Perspectiva, 2001.

NEOTTI, Clarêncio. Frei Bruno Linden: Tudo para Todos. Vila Velha: $3^{\text {a }}$ Edição: ABBA Editora, 2014.

SÊGA, Cristina. O kitsch está Cult. In IV Encontro de estudos multidisciplinares em cultura. UFBA, Salvador, 2008. STRICKLAND, Carol. Arte comentada.

SÊGA, Christina. O Kitsch e suas dimensões. Brasília: Casa das Musas. 2008

TROMBETTA, Gerson Luiz. Entre a lágrima e a transgressão: a ambiguidade do kitsch no projeto moderno da arte e da arquitetura [online]. Disponível em: http://seer.upf.br/index.php/rhdt/article/view/5651. Acesso em 29 de mai. 2019.

ZÍLIO, Alessandra; COLERAUS, Vanessa. Conversa de Santos: Frei Bruno e Frei Edgar. Edição particular, Joaçaba 1998. 56 p.

(Org). Dicionário de ciências sociais. $2^{\mathrm{a}}$ Edição. Rio de Janeiro: Fundação

Getúlio Vargas, 1987. 